\title{
Tecendo desejos: o fazer e o desfazer do desenho da vida em em A moça tecelã de Marina Colassanti
}

Resumo: Esta análise se propõe fazer uma leitura de A Moça Tecelã de Marina Colasanti sob o olhar que busca na obra literária a construção dos nossos sentidos pelo sentido da própria obra. A práxis da leitura dos elementos textuais relacionada aos referentes que identificamos em nosso contexto cultural fornece condições para a significação e ressignificação do leitor. Com base no sincretismo da linguagem verbal e visual repleto de significação à espera da decodificação do leitor, descreveremos o porquê essa obra tratase de uma literatura que dialoga com o leitor, deixando um espaço aberto para reflexões sobre a sociedade contemporânea, ao utilizar linguagem e referentes do passado, mas com as ideais e comportamentos do presente. Para tanto, utilizamos o conceito de imagem de Santaella (2008), de intertextualidade de Carvalhal (2006) e imaginário cultural de Gregorin Filho (2006).

Palavras-chave: Literatura infantil. Imagem. Imaginário cultural. Intertextualidade.

Abstract: This is a literary analysis which intends to read and describe the Children's Literature book named A Moça Tecelã by Marina Colasanti. The approach considers the meaning construction of the reader by the way the book narrative was built, that is, the word read within the illustrations. Therefore, the author created a story that dialogues with the fairy tale genre but also making a rupture in its form to bring the narrative to the readers present time. The main theory to support this analysis is the image concept by Santaella (2008), intertextuality by Carvalhal (2006) and cultural imaginary by Gregorin Filho (2006).

Keywords: Children's literature. Illustration. Image. Cultural imaginary.

\section{Introdução}

A impecável obra literária A Moça Tecelã de Marina Colasanti conta a história de uma jovem que, através de seu tear mágico, tece todos os seus desejos transformando-os em realidade. A princípio, esse poder de realização poderia parecer suficiente em si mesmo para garantir uma história sem conflitos e feliz. Entretanto, a moça tecelã não tem certezas absolutas, isto é, verdades prontas e definitivas somente à espera de acontecerem e darem certo. Com isso, a história passa por escolhas

\footnotetext{
${ }^{1}$ Doutoranda no Programa de Pós Graduação em Estudos da Tradução da Universidade de São Paulo (USP). E-mail: gisele.rosa@usp.br
} 
conflitantes da personagem principal, como casar-se e o marido passar a dominar sua vida, que a levam a aprender com os erros até que se reestabeleça o equilíbrio em sua história. Vemos que a narrativa cria uma identificação bem construída para que jovens leitoras possam aderir. Isso porque, como este texto exemplar ${ }^{2}$ demonstra, é no fazer e desfazer de nossas ações, resultando sempre em experiências, que o indivíduo pode encontrar melhores caminhos para percorrer e evoluir sua percepção sobre o que realmente deseja.

A presente análise se propõe fazer uma leitura de A Moça Tecelã precisamente sob esse olhar que busca na obra literária a construção dos nossos sentidos pelo sentido da própria obra. A práxis (BLIKSTEIN, 2003), pela leitura dos elementos textuais relacionada aos referentes que identificamos em nosso contexto cultural, fornece condições para a significação argumentada a seguir.

Por fim, com base no sincretismo da linguagem verbal e visual repleto de significação à espera da decodificação do leitor, veremos, em seguida, o porquê dessa obra tratar-se de uma literatura que dialoga com o leitor, deixando um espaço aberto para reflexões sobre a sociedade contemporânea, ao utilizar linguagem e referentes do passado, mas com as ideias e comportamentos do presente.

\section{A imagem, a palavra e suas correspondências}

Partindo, primeiramente, da análise das imagens ${ }^{3}$ de $A$ Moça Tecelã, poderíamos destacar como principal função da ilustração (cf. Camargo, 1995) a Estética, uma vez que elas são construídas a partir de bordados reais, isto é, linhas e tecidos de verdade que compõem lindos bordados fotografados chamando a atenção para seus detalhes, cores e desenhos.

No entanto, nessa leitura, preferimos destacar como primeira função da ilustração a função simbólica. A razão pela qual essas ilustrações foram bordadas

\footnotetext{
${ }^{2}$ O exemplar, aqui, é sem a conotação de se "encerrar com moralidade" (COELHO, 1984) dos contos exemplares, mas sim de sugerir um "exemplo de conduta" que propõe ao leitor, nessa obra, a possibilidade de mudança, isto é, de transformação de si mesmo e de seus atos. Ainda, diria estar mais relacionado ao mito de Mircea Eliade (1963): "uma 'história verdadeira' e sobretudo, altamente preciosa, porque sagrada, exemplar e significativa" (p.9).

${ }^{3} \mathrm{O}$ conceito de imagem utilizado aqui é como representação visual: "objetos materiais, signos que representam o nosso meio ambiente visual". Cf. Santaella e Nöth (2008, p. 39).
} 
verdadeiramente, criando uma impressão de que estamos dentro da história da jovem em que "tecer era tudo o queria fazer", é justamente a sua relação entre "tear"/"bordado" e "realização de seus desejos". A moça está tecendo seus desejos em um tear e o leitor está lendo-os também na forma de imagens bordadas, construindo então uma metáfora do texto verbal. A vida da jovem é construída através do tear assim como a imagem que o leitor tem acesso à sua história.

A partir dessa leitura, não podemos deixar de citar outra função da ilustração que também caracteriza as imagens de A Moça Tecelã, a descrição. A cada página da história, enquanto o texto verbal vai narrando os fatos, temos em paralelo uma imagem que os apoia ou sustenta, descrevendo os cenários e personagens, ou seja, há um diálogo entre o verbal e o visual. Por exemplo, as cores dos bordados dialogam com o estado de espírito da personagem principal. Quando ela está tecendo em liberdade, feliz e com o controle de sua vida, temos uma diversidade de cores vibrantes e quentes. E nos momentos em que a jovem tecelã está se submetendo à vontade alheia, de seu marido, enclausurada e triste, temos cores frias e monocromáticas.

Em outro exemplo, vemos também um paralelismo entre imagem e texto na construção da imagem da moça tecelã, especificamente. No início da narrativa, quando a jovem detinha o controle de sua vida, sua imagem transparece liberdade e leveza, não somente por ser colorida, mas também pelos seus cabelos soltos e pés descalços sobre a relva, além do contorno nítido de sua imagem.

A partir do momento que ela tece seu marido, começa a sua transformação física, gradualmente; primeiro, com os cabelos ajeitados para trás com uma fita, que poderíamos interpretar como um sinal de anuência à nova vida regrada e limitada com a chegada desse homem. Segundo, pela sua posição física em relação a ele e a ela própria, isto é, temos aqui uma relação semiótica de superioridade e inferioridade, pois antes da chegada do marido, a jovem se apresenta de pé e em simetria com as árvores que teceu, parecendo até que está em movimento, envolta pelas linhas que comanda como quer; posteriormente, enquanto permite que o marido dite o que ela deve ou não tecer, vemola sempre sentada ao tear, abaixo da linha onde ele se encontra, perdendo a nitidez de seu contorno, como uma metáfora da perda de sua identidade.

Já no terceiro momento da história, quando a jovem passa pela experiência dolorosa e aprende com ela, vemo-la novamente colorida, de cabelos soltos e com contornos definidos, envolta por suas linhas, deitada sobre a relva. Deitada sim, porém 
sem a conotação de inferioridade, pois o homem não está lá em contraste. Além disso, na capa de trás da edição analisada, temos representado esse mesmo momento narrativo, com a diferença de que, aqui, a jovem está em posição vertical, e não horizontal. Isto é, a posição não está contradizendo a construção de sentido e sim enfatizando uma tranqüilidade e conforto, ou em outras palavras, a sua liberdade reconquistada.

Podemos concluir que a imagem está ampliando o texto verbal, uma vez que todos esses significados são construídos a partir do texto, que aponta uma direção para o significado, mas sem reduzi-lo, pelo contrário, pois abre a visão do leitor para um universo colorido e expressivo. Isso ocorre porque não temos na imagem uma descrição realista ou perfeita em termos de representação "fiel" às palavras lidas no texto. A imagem amplifica o sentido do texto por ser tão rica simbólica e esteticamente, trazendo formas e cores em um conjunto expressivo, repleto de significados que o leitor irá construir.

\section{As vozes e os textos que se intercalam em nosso conto}

A história de A Moça Tecelã não apresenta dificuldades para ser enquadrada no gênero de contos de fadas. Para isso, podemos citar o maravilhoso, presente na história como o tear, mediador mágico que se encontra entre a materialidade do ser humano e a realização de seus desejos; o cenário, com seu palácio, estrebarias, cofres de moedas e salas de criados; e uma jovem solitária que deseja um marido ao seu lado de chapéu emplumado, rosto barbado e corpo aprumado (COLASANTI, 2004).

De acordo com Coelho (1981), um conto de fadas pressupõe a realização de sonhos, ação representada pela fada, do latim fatum e também fado, em outras palavras, o destino, aquilo que se considera irrevogavelmente destinado na vida de nossos personagens. Além disso, Coelho (idem) também faz uma associação da "imagem da Mulher em seu significado primitivo e secreto" com as fadas: "o feminino está mais próximo ao elemento cósmico, (...) mais imediatamente incorporado aos grandes ciclos da natureza. (...). A mulher é destino, é tempo, é a lógica orgânica do próprio futuro" (p. 88).

A caracterização da mulher, acima, pelo filósofo Spengler que Coelho (1984) destaca em seu livro, orienta nossa interpretação sobre a representação da jovem tecelã 
como sendo a "força primordial, necessária e, ao mesmo tempo, temida, e por isso mesmo continuamente dominada pelo homem" (p. 88).

A figura feminina que historicamente foi representada na cultura ocidental sendo submetida às tentativas do homem em dominá-la, tê-la sob seu poder, é retomada em $A$ Moça Tecelã, pois ela não só detém o poder de realização de sonhos, dela e posteriormente do marido, como também é submetida temporariamente ao jugo deste marido.

Entretanto, em nossa história, após viver a experiência e consequências de seus desejos, a jovem consegue agir e livrar-se da dominação, desfazendo o desenho que havia tecido no tear. Há uma ruptura na narrativa que a diferencia dos contos de fadas em que a princesa submete-se a qualquer situação em prol da sua união com o príncipe. Aqui, depois de se dedicar aos desejos intermináveis do seu príncipe que somente ela tem o poder de proporcionar, nossa princesa percebe que se anulou completamente nessa relação, e decide optar por si mesma e não por ele. É muito simbólico o gesto de desmanchar todo o tecido, incluindo o próprio príncipe, pois sugere a dificuldade de voltar atrás em nossas decisões, uma vez tomadas erradamente, e recomeçar.

Assim, podemos ouvir duas vozes nesse texto, isto é, dois discursos que se relacionam na construção desse significado: o discurso do passado, pois a submissão feminina da esposa ao marido, marcada em vários séculos da cultura ocidental e oriental; e o do presente: independência feminina, fenômeno mais recente, a partir do século 20 na cultura ocidental, que permite à mulher decidir os rumos de sua vida profissional, isto é, a de ser a realizadora de seus sonhos, e de sua vida afetiva, decidindo se deseja permanecer ou não em um relacionamento amoroso.

A primeira impressão que temos é a de que estamos lendo uma história antiga, um tradicional conto de fadas e que, de repente, se atualiza debaixo de nossos olhos pela leitura que fazemos com as "lentes sociais" de nosso tempo. "(...) A diferença entre o presente e o passado é que o presente consciente corresponde a um entendimento do passado de uma maneira e de numa escala que a consciência que esse passado tem de si mesmo não pode mostrar" (Eliot, 1989, apud CARVALHAL, 2006, p. 63).

Nesse processo de leitura intertextual, podemos identificar o que Carvalhal (2006) destaca como "(...) distanciamento da idéia de reprodução [de um mesmo texto] 
para se ampliar num significado maior, de atitude crítica que a nova obra adota em relação àquelas que a antecederam (idem)".

Ou seja, a leitura de um conto de fadas atual ${ }^{4}$ que traz elementos tradicionais desse gênero, como mencionamos anteriormente, pode prolongar os valores que pertenciam à sua tradição ou rompê-los. Em A Moça Tecelã, valendo-se da tradição formal dessa literatura, a autora apresenta novos valores, atualizados, revitalizando a tradição e "invertendo o estabelecido" (ibidem).

Veremos a seguir, mais detalhadamente, como se dá essa significação no texto e os referentes culturais que fazem parte do imaginário da escritora e do leitor que possibilitam essa leitura.

\title{
4. O papel da mulher e suas significações no imaginário cultural
}

\begin{abstract}
"Quando uma pessoa cria uma imagem, ela pode ter sido sugerida pelo seu inconsciente ou pelo inconsciente de seu grupo, manifestando-se no seu (...). A imagem significa, então, um tipo de expressão simbólica condensada de experiência humana" (MELLO E SOUZA, 2004, p. 48).
\end{abstract}

A citação de Cândido demonstra a importância de se refletir sobre a influência e composição do imaginário cultural na vida de uma sociedade, principalmente quando se trata de uma representação literária, isto é, uma forma, tal como a literatura infantil e suas mensagens a serem decodificadas, como vemos em A Moça Tecelã.

A narrativa presente na Literatura Infantil (pós-segunda metade do século 19) destaca-se pela possibilidade do leitor estar em contato com textos vinculados às "práticas sociais que foram se impondo na comunidade e na educação das novas gerações (...)" (GREGORIN, 2006, p. 6). De acordo com Gregorin, os textos:"(...) fazem alusão a temas fundamentais da sociedade e frutos da experiência individualsocial-cultural, como a questão do gênero, da alteridade, das tradições culturais e religiosas, entre outros" (p. 6).

Dessa forma, vemos que a literatura é formada de um conteúdo ideológico que no momento de expressa-lo é passível de (des)construção de significados pelo leitor. Em outras palavras, essa grande esfera cultural em que o indivíduo está inserido,

\footnotetext{
${ }^{4}$ A Moça Tecelã foi publicado em 2004 e está em sua 2a reimpressão - 2008.
} 
oferece-lhe condições de construir ou desconstruir significados presentes em uma literatura que foi produzida nesta e para esta sociedade. Essa (de)codificação de significados somente é possível por causa do inconsciente coletivo compartilhado, isto é, o imaginário cultural:

"(...) o imaginário das sociedades é nutrido de um fazer constante, um fazer cultural que produz informações de natureza perceptiva, isto é, imagens obtidas pela experiência visual dessa sociedade (...). Essas imagens, por serem construídas de maneira a possuírem uma parte material e outra abstrata que remete a um tema, são figuras a que recorremos no momento da produção de textos, textos esses que têm como objetivo a manutenção, a discussão ou a transformação de valores nos quais essa mesma sociedade se alicerça. (GREGORIN, 2002, p. 9 - marcação nossa)"

E é por esse objetivo inerente dos textos que destacamos a reflexão sobre o papel da mulher em nossa obra, aqui, marcadamente em discutir e/ou transformar valores nos quais nossa sociedade se alicerça.

Em A Moça Tecelã, como vimos anteriormente, há uma ruptura na narrativa, em que ao deparar-se pela experiência com uma situação de submissão ao marido e seus desmandos, a jovem decide por desfazer essa relação e restabelecer sua liberdade, e consecutivamente, a sua felicidade.

Gregorin (idem) destaca que, na era pós-lobatiana e contemporânea, um novo momento no percurso da arte se sobrepõe aos paradigmas tradicionais, os chamados paradigmas emergentes. Aqui, encontramos novos modelos que se contrapõem ao conservadorismo conteudístico e formalista que marcaram a literatura infantil até este momento.

Podemos citar, dentre os paradigmas emergentes, com o intuito de ilustrar nossa argumentação, três deles que se encontram em nossa obra em oposição direta aos paradigmas tradicionais, respectivamente: Individualidade consciente $\mathrm{X}$ Individualismo; Descrédito da autoridade X Obediência absoluta; e Anti-preconceito X Preconceitos (ibidem).

A nossa personagem principal apresenta-se, inicialmente, só na história, entretanto não sozinha: "nada lhe faltava" (COLASANTI, 2008, p. 4). Em seguida, revela-se sim sozinha, e imediatamente resolve esse problema, tecendo para si o marido. Como o marido acaba por revelar-se autoritário e incompreensível, a moça tecelã desfaz 
o relacionamento desmanchando-o em seu tear. Daí para frente, volta ao status só, novamente sem a conotação de sozinha, isto é, sem que isso caracterize tristeza, pelo contrário, está livre e sob o comando, outra vez, de seus próprios desejos.

Esse breve resumo justifica os paradigmas emergente citados, pois constatamos que a jovem representa um individualismo consciente, diferentemente do individualismo tradicional que mantém suas verdades absolutas, a moça tecelã parte para a experiência e reavalia seus desejos e decisões. Vemos também, o questionamento que ela faz à autoridade que tenta se impor: o marido. Ao invés de praticar a obediência absoluta, tanto aos padrões sociais estabelecidos, como aos valores dessa autoridade, isto é, a submissão da esposa, a jovem identifica o que é melhor para si e toma a atitude da transformação. Por fim, temos como consequência a negação do preconceito, ou seja, a moça tecelã rompe com os padrões que ditariam a manutenção do casamento a qualquer preço, optando por sua felicidade, ainda que a sociedade diga o contrário.

\section{Considerações finais}

Concluímos que todas as argumentações presentes nessa análise, inclusive sob a luz dos paradigmas emergentes em oposição aos tradicionais sobre a representação do papel da mulher em A Moça Tecelã, convergem em dois pontos: o primeiro indica que essa análise foi possível de se realizar somente e precisamente por compartilharmos, autora e leitores, críticos ou não, do mesmo imaginário, esse "sistema organizador de imagens, comportando um conteúdo semântico, uma estrutura e uma visão de mundo" (MELLO, 2007, p. 42). Sem esse conhecimento, esse receptáculo coletivo de imagens significativas, não seria possível depreender tais interpretações, tampouco construir argumentos que decifraram a mensagem aqui desnudada.

O segundo ponto, voltando à teoria dos paradigmas emergentes, trata do nosso destaque para o principal deles que acaba por resumir A Moça Tecelã: seu caráter como obra de arte. Há uma oposição ao paradigma tradicional que a literatura infantil se utilizava como um "recurso pedagógico" (GREGORIN, 2007, p.10), em que uma única voz prevalecia e transmitia os valores das classes dominantes, isto é, um instrumento pedagógico mantenedor do status quo. Em A Moça Tecelã, pelo contrário, temos o elemento literário, a conjunção de suas imagens e texto que formam uma linguagem 
dialógica com o leitor sobre valores que precisam ser repensados, uma proposta sobre a transformação de nossas atitudes contribuindo para uma evolução e reflexão interior.

\section{Referências}

BLIKSTEIN, Izidoro. Kaspar Hauser ou A Fabricação da Realidade. São Paulo: Ed.Cultrix, 2003.

CAMARGO, Luís. Ilustração do Livro Infantil. Belo Horizonte, MG: Editora LÊ, 1995. CARVALHAL, T.F. Literatura Comparada. São Paulo: Ática: 2006.

"Intertextualidade: a migração de um conceito". In: Revista Via Atlântica. No. Vol-09. Ano-junho/2006, p. 125-136.

COELHO, N. N. Literatura Infantil: Teoria. Análise. Didática. São Paulo: Moderna, 1993.

Panorama Histórico da Literatura Infantil/Juvenil. São Paulo: Ática, 1984.

COLASANTI, M. A moça tecelã. São Paulo: Global, 2008.

DURAND, G. A imaginação simbólica. Lisboa: Edições 70, 1993.

ELIADE, M. Aspectos do mito. Lisboa. Edições 70, 1989.

GREGORIN FILHO, J. N. Figurativização e imaginário cultural. Tese de doutoramento. UNESP-Araraquara, 2002

Literatura Infantil: perspectivas de ensino e pesquisa. In: SANTOS, GENS (org) VEncontro de Literatura Infantil e Juvenil: leitura e crítica. RJ: UFRS, 2008, p. 01-12.

Literatura Infantil-Juvenil: diálogos com a sociedade. In: IV Congresso de Letras da Universidade do Estado do Rio de Janeiro. São Gonçalo, RJ, 2007, MELLO, Ana Maria Lisboa de. Mito e Literatura. Revista Ciências e Letras, 42. Porto Alegre: Fapa, 2007.

MELlO e SOUZA, Antonio Candido. Estudo Analítico do Poema. São Paulo: Ed. Humanitas, 2004.

Santaella, L e Nöth, W. Imagem: cognição, semiótica, mídia. São Paulo: Iluminuras, 2008.

"Três tipos de leitores: contemplativo, movente e imersivo" In: Navegar no Ciberespaço: o perfil cognitivo do leitor imersivo. Ed. Paulus, 2004. 